\title{
Pembangkit Listrik Termoelektrik Terintegrasi Kompor Sekam Padi
}

\author{
YR. Liana ${ }^{1,2}$ *, A. Yulianto ${ }^{1}$, I. Yulianti ${ }^{1}$ \\ ${ }^{1}$ Program Studi Pendidikan Fisika, Pascasarjana Universitas Negeri Semarang, Jl. \\ Kelud Utara III Kota Semarang 5023, Indonesia. \\ 2 SMA Negeri 2 Batang, Jl. Desa Rowobelang, Kab. Batang 51222, Indonesia. \\ *Penulis Penanggungjawab. E-mail: yrimaliana21@gmail.com \\ Telp: 081326824896
}

\begin{abstract}
ABSTRAK
Penggunaan bahan bakar menjadi kebutuhan sehari-hari rumah tangga terutama untuk memasak. Keterbatasan persediaan bahan bakar gas menyebabkan peralihan ke bahan bakar alternatif seperti penggunaan kompor sekam padi. Ruang pembakaran dirancang untuk mencapai pembakaran sempurna dengan meningkatkan efisiensi dan mengurangi polusi udara dalam ruangan. Pengembangan tambahan yang diperkenalkan dalam penelitian ini, melibatkan penggunaan 6 modul generator termoelectric TEC1-12706 yang dirangkai secara seri untuk membangkitkan energi listrik untuk penerangan dan pengisian daya handphone. Uji eksperimental sederhana dilakukan dengan menvariasikan massa sekam padi 200 gram dan 500 gram. Hasil penelitian ini didapatkan tegangan output maksimum sebesar 6,21 volt dan arus yang masuk ke baterai sebesar 2,40 A yang dapat digunakan untuk penerangan dan pengisian daya handphone sampai $70 \%$ dari daya awalnya yang dicapai untuk bahan bakar 500 gram sekam padi.
\end{abstract}

Kata Kunci : Generator Termoelectrik, kompor sekam padi, pembangkit energi listrik. 


\begin{abstract}
The use of fuel is a daily necessity for the household, especially for cooking. Limited supply of natural gas causes a shift to alternative fuels such as the use of rice husk stoves. The combustion chamber is designed to achieve complete combustion by increasing efficiency and reducing indoor air pollution. Additional development introduced in this study, involves the use of 6 TEC1-12706 thermoelectric generator modules arranged in series to generate electrical energy for lighting and charging mobile phones. A simple experimental test was carried out by varying the mass of rice husk 200 grams and 500 grams. The results of this study obtained a maximum output voltage of 6.21 volts and a current entering the battery of 2.40 A which can be used for lighting and charging mobile phones up to $70 \%$ of the initial power achieved for 500 grams of rice husk fuel.
\end{abstract}

Keywords: Thermoelectric Generator, rice husk stove, electric energy generator.

\section{Pendahuluan}

Dewasa ini penggunaan listrik kian meningkat, sedangkan tarif listrik tiap tahun selalu naik. Hal ini tentu saja sangat disayangkan mengingat kenaikan tarif listrik dapat memberikan dampak kurang baik bagi stabilitas harga-harga kebutuhan lain di pasaran. Oleh karena itu, perlu adanya inovasi pembangkit listrik free energy guna memperkecil biaya yang harus di keluarkan oleh masyarakat. Salah satu perangkat yang termasuk kedalam pembangkit listrik free energy adalah Termoelektrik Generator (TEG).

Indonesia sebagai negara pertanian menghasilkan limbah sekam padi yang jumlahnya melimpah, apabila tidak ditangani dengan baik dapat menimbulkan masalah bagi lingkungan.
Lingkungan tidak dapat menguraikan sekam dengan cepat karena sekam memiliki kandungan selulosa yang tinggi $[1,2]$.

Lertsatitthanakorn [3], menciptakan sistem yang memanfaatkan proporsi panas limbah biomass dengan daya keluaran 2,4 $\mathrm{W}$ dan 4,2 W ketika perbedaan suhu $150{ }^{\circ} \mathrm{C}$ dan efisiensi 3,2 \% mampu untuk menghidupkan radio portable kecil atau bola lampu pijar berdaya rendah. Nuwayhid et al.[4], membuat desain generator menggunakan modul termoelektrik sebagai pembangkit listrik. Hasilnya didapatkan 4,2 W mampu dibangkitkan pada sistem ini. Para penulis telah menunjukkan keuntungan ekonomi yang dapat diterima [5].

Kalor yang dihasilkan, selain untuk keperluan memasak juga dapat dimanfaatkan sebagai penghasil listrik. Dengan memanfaatkan efek seebeck melalui 
melalui generator termoelektik, atau juga disebut seebeck generator yaitu perangkat generator listrik yang mengkonversikan panas karena perbedaan suhu menjadi energi listrik. Semakin besar nilai perbedaan suhu, maka listrik yang dihasilkan juga semakin besar [6]. Pemanfaatan generator termoelektrik sebagai pembangkit listrik juga merupakan salah satu langkah untuk menanggulangi seputar masalah kelistrikan yang terjadi di masyarakat [7].

Berdasarkan permasalahan tersebut, penelitian ini bertujuan untuk mendesain pembangkit listrik termoelektrik [8] terintegrasi kompor biomassa sekam padi, sehingga fungsi kompor dapat ditingkatkan selain untuk memasak, juga dapat menghasilkan listrik untuk penerangan dan pengisian daya baterai handphone.

\section{Bahan dan Metode}

\subsection{Alat dan Bahan yang digunakan}

1. Tungku kompor

2. Modul termoelektrik TEC1 - 12706

3. Heatsink

4. Blower 12 VDC

5. Sensor suhu DS18B20

6. Multimeter digital

7. USB port charger

8. Lampu LED 5 V DC

9. Neraca digital

10.Stopwatch

11.Bak air

12.Sekam padi

\subsection{Flowchart Metode Penelitian}

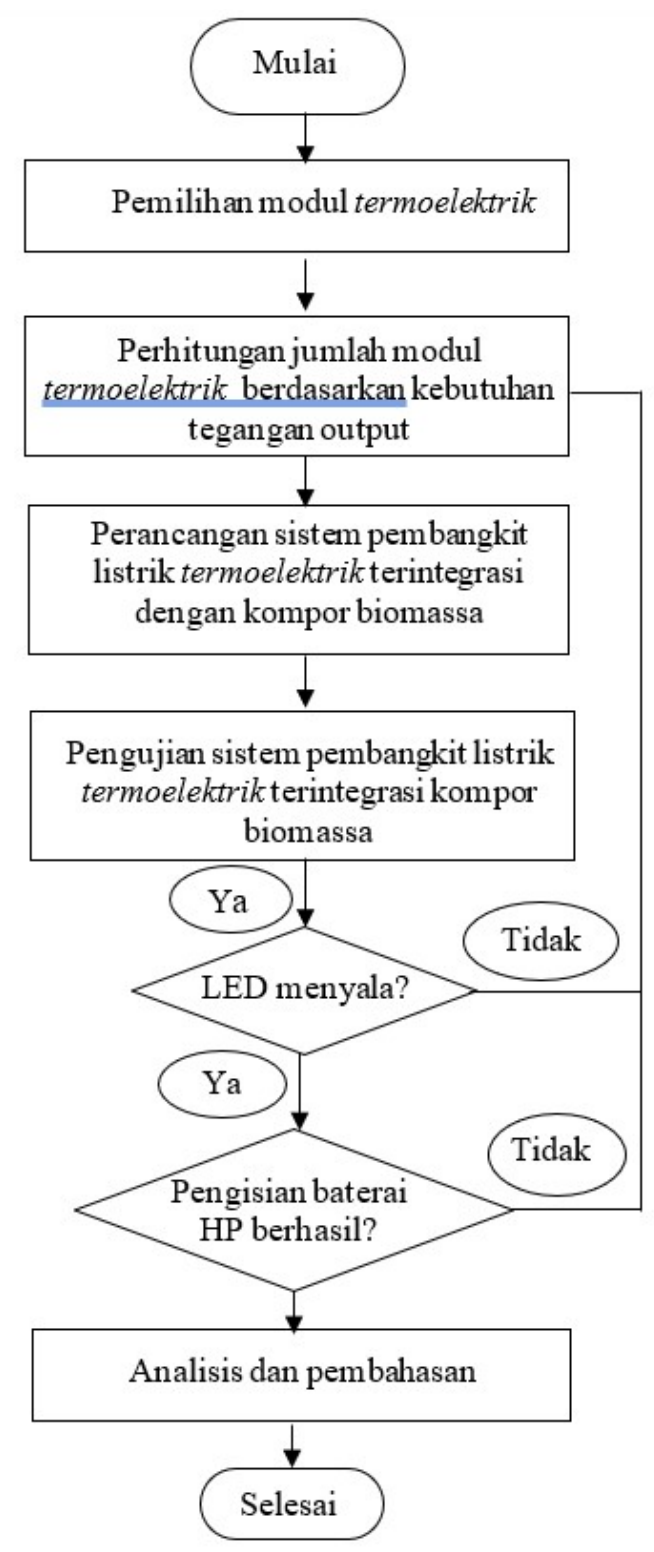

\subsection{Pemilihan modul termoelectric}

Modul Termoelektrik yang digunakan dalam penelitian ini adalah TEC1 12706. Modul ini dipilih karena mudah didapatkan di pasaran. Termoelektrik TEC1-12706 terdiri dari sekumpulan semikonduktor tipe-p dan tipe-n yang dihubungkan dalam sebuah rangkaian tertutup, dibungkus material keramik, berdimensi $40 \times 40 \times 5 \mathrm{~mm}^{3}$. Modul termoelektrik berfungsi sebagai 
pendingin pada salah satu sisi dan sebagai pemanas pada sisi lainya apabila diberi aliran listrik arus searah, namun apabila alat ini di kedua sisinya diberi suhu yang berbeda, maka akan menghasilkan listrik arus searah. Spesifikasi TEC1-12706 ditunjukkan tabel 1.

Tabel 1. Data Sheet TEC1-12706 [7]

\begin{tabular}{ccc}
\hline Temperatur sisi panas & $25^{\circ} \mathrm{C}$ & $50^{\circ} \mathrm{C}$ \\
\hline $\mathrm{Qmax}_{\max }(\mathrm{W})$ & 50 & 57 \\
\hline $\mathrm{DT}_{\max }\left({ }^{\circ} \mathrm{C}\right)$ & 66 & 75 \\
\hline $\mathrm{I}_{\max }(\mathrm{A})$ & 6,0 & 6,4 \\
\hline $\mathrm{V}_{\max }(\mathrm{V})$ & 14,4 & 16,4 \\
\hline $\mathrm{R}(\mathrm{W})$ & 1,98 & 2,30 \\
\hline
\end{tabular}

2.4 Perhitungan jumlah modul Berdasarkan kebutuhan tegangan output yang dibutuhkan

Berdasarkan data sheet modul peltier TEC1-12706, Tegangan yang diperoleh untuk tiap satu keping termoelektrik sebesar 0,9V (tanpa pembebanan), maka dibutuhkan 6 keping modul termoelektrik yang disusun secara seri. untuk pengisian daya baterai handphone atau menyalakan lampu LED 5 VDC.

\subsection{Perancangan sistem pembangkit} listrik termoelektrik terintegrasi dengan kompor biomassa

Secara keseluruhan desain pembangkit listrik termoelektrik terintegrasi kompor biomassa dalam penelitian ini diperlihatkan pada gambar 2.

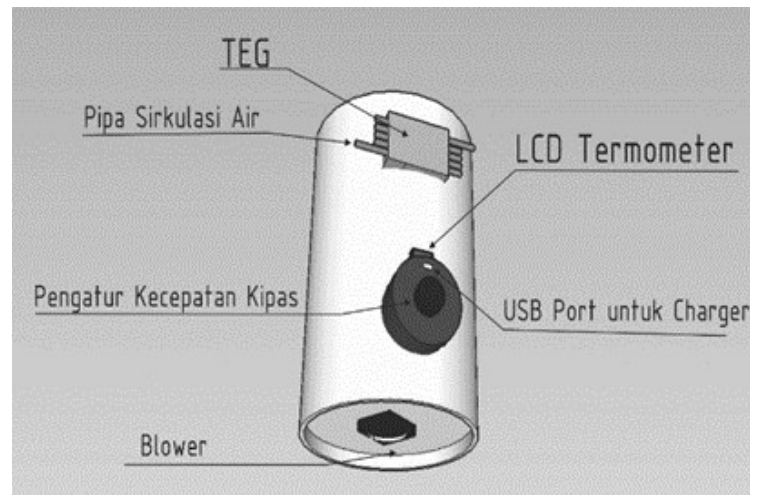

Gambar 2. Desain kompor sekam padi dengan termoelektrik

Kompor sekam padi dalam penelitian ini berbentuk tabung terbuat dari bahan alumunium untuk bagian luar dan stainless steel untuk bagian dalamnya. Terdapat beberapa lubang besar di bagian bawah kompor dengan tujuan untuk memasok oksigen, gas yang dibutuhkan dalam proses pembakaran. Di bagian dalam kompor terdapat tempat yang berfungsi sebagai tungku pembakaran sekam padi. Bagian atas kompor dilengkapi dudukan tempat meletakkan alat memasak. Kompor sekam padi menghasilkan api yang cukup besar lantaran sirkulasi udara yang terjaga dengan baik. Panasnya mampu mendidihkan 1 liter air dalam waktu 5 hingga 10 menit. Kompor ini juga dilengkapi dengan LCD termometer untuk mengukur suhu panas, USB port untuk charger handphone dan pengatur kecepatan kipas yang berfungsi memperkecil atau memperbesar nyala api, termasuk mematikan kompor. Listrik dihasilkan oleh generator termoelektrik yang terpasang pada badan kompor. Generator 
termoelektrik berfungsi mengubah energi kalor yang dihasilkan nyala api menjadi energi listrik.

Bagian dalam kompor, listrik diperlukan untuk memberi daya pada kipas karena udara yang bertiup melalui kompor meningkatkan rasio udara/bahan bakar dan mencapai pembakaran sempurna. Pada awal pembakaran, suhunya sangat rendah, sehingga perlu mengisi baterai. Baterai membantu menjalankan kipas selama beberapa menit pertama pembakaran ketika pelat panas belum cukup panas untuk menghasilkan listrik. Bagian termal kompor dihasilkan dari enam modul TEC1 - 12706 yang disusun seri pada heatsink. Heat sink aluminium dipasang di sisi dingin modul termoelektrik. Termal pasta digunakan untuk meningkatkan perpindahan panas antar permukaan. Dua sistem pendingin yang berbeda diuji untuk mempertahankan suhu konstan pada sisi dingin (air es yang suhunya dikontrol).

Material sisi pemanas kompor dihasilkan dari pembakaran sekam padi, sementara material pada sisi dingin menggunakan air es. Hal ini disebabkan es mempunyai titik lebur yang sangat baik, air es bisa sampai menembus nol derajat celcius [9]. Jika satu sisi modul panas dan sisi lainnya dingin, maka energi listrik akan dihasilkan. Arus listrik akan distabilkan oleh stabilizer sebelum dialirkan melalui kabel yang tersambung ke USB port. Dari situlah, energi listrik energi listrik yang dihasilkan bisa dimanfaatkan untuk menyalakan lampu atau mengisi baterai handphone.

\subsection{Pengujian dan pengukuran output sistem pembangkit listrik termoelektrik terintegrasi kompor biomassa}

Pengujian dan pengambilan data sistem pembangkit listrik termoelektrik terintegrasi kompor sekam padi untuk penerangan atau untuk pengisian daya baterai handphone dilakukan setiap 10 menit sekali dengan menggunakan multimeter. Bahan bakar kompor berupa sekam padi dengan variasi massa 200 gram dan 500 gram. Pemilihan variasi massa tersebut dilakukan dengan mempertimbangkan kapasitas maksimum penampung bahan bakar dalam kompor. Beban pemanasan digunakan panci masak berisi 1 liter air dan beban listrik digunakan lampu LED atau charger handphone. Langkah pengambilan data dari pengujian pembangkit listrik termoelektrik terintegrasi kompor sekam padi, yaitu: (1) memasang multimeter secara paralel sebelum rangkaian USB buck converter untuk mengukur tegangan inputnya, (2) mengukur besar tegangan input sampai multimeter menunjukan angka yang konstan dan tidak berubah lagi, (3) mengukur besar arus input yang dihasilkan dengan cara memasang multimeter secara seri sebelum rangkaian USB buck converter, (4) memasangkan multimeter secara paralel sesudah 
rangkaian USB buck converter untuk mengukur tegangan outputnya, (6) Setelah besar tegangan output konstan, mengukur besar arus output yang dihasilkan dengan cara memasang multimeter secara seri sesudah rangkaian USB buck converter [10]

Instalasi uji coba pembangkit listrik termoelektrik terintegrasi kompor berbahan bakar sekam padi ditunjukkan gambar 3 .

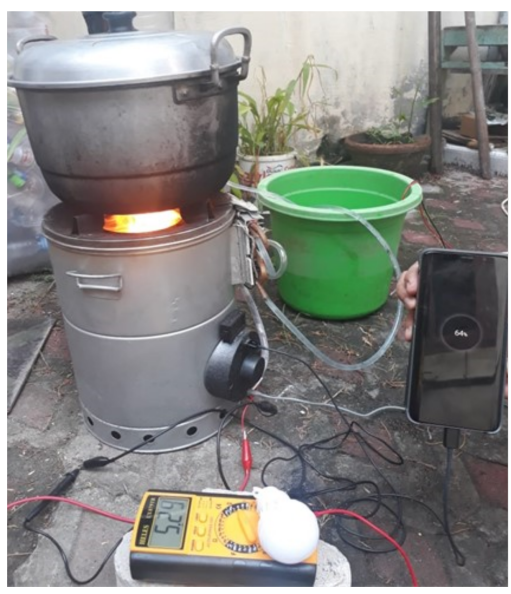

Gambar 3. Pembangkit listrik termoelektrik terintegrasi kompor sekam padi

\section{Hasil dan Pembahasan}

Dari hasil pengujian atau pengambilan data pada pembangkit listrik termoelektrik terintegrasi kompor berbahan bakar sekam padi diperoleh hasil data sebagai berikut:

Dari tabel 2 dapat dilihat bahwa sistem pembangkit listrik termoelektrik dengan bahan bakar 200 gram sekam padi, pada tegangan dan arus listrik yang dihasilkan sebesar 5,00 V dan 1,93 A.

Dari tabel 2 dapat dilihat bahwa sistem pembangkit listrik termoelektrik dengan bahan bakar 200 gram sekam padi, pada 10 menit pertama air dalam panci masak sudah mendidih, namun pembakaran hanya menghasilkan tegangan output sebesar $2,16 \mathrm{~V}$ dengan besar temperatur sisi panas dari generator thermoelectric $73,5{ }^{\circ} \mathrm{C}$. Tegangan yang dihasilkan ini belum mencukupi untuk menyalakan lampu LED atau mengisi daya baterai handphone sebesar $5 \mathrm{~V}$.

Tabel 2. Hasil pengujian kompor dengan bahan bakar 200 gram sekam padi sekam

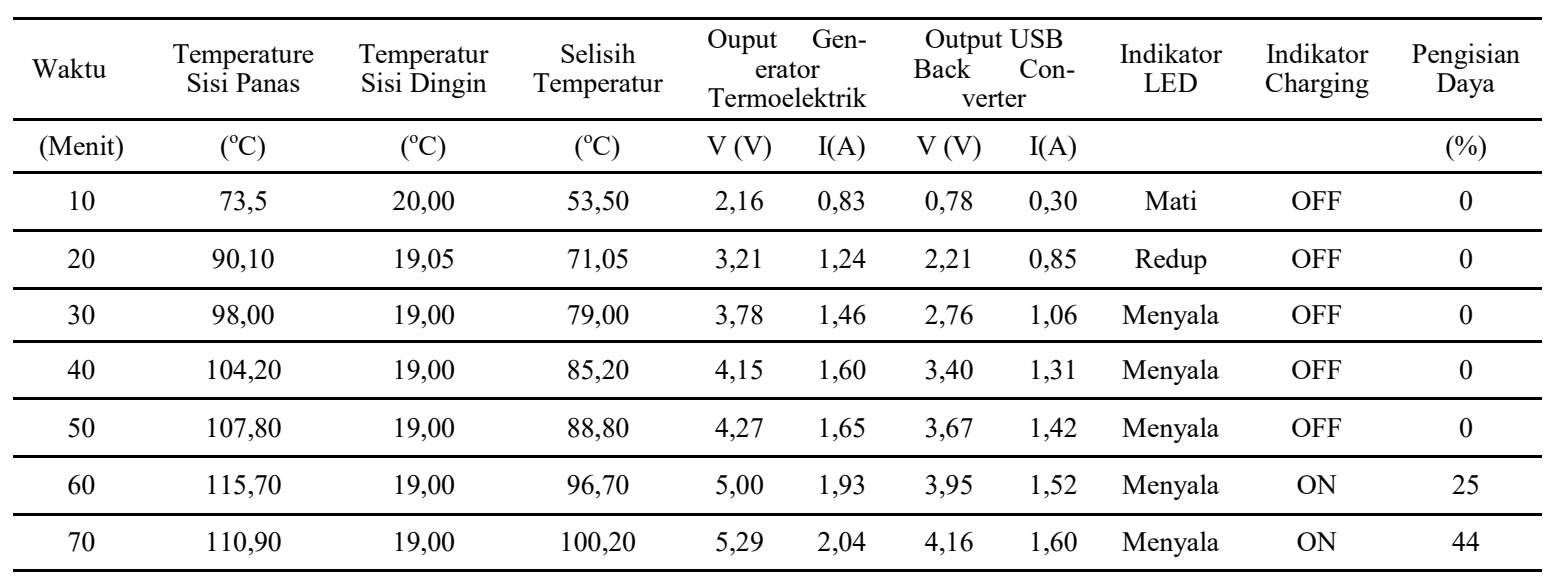


Pada menit ke - 30 dihasilkan tegangan sebesar $3,78 \mathrm{~V}$ dengan temperatur sisi panas dari generator thermoelectric sebesar $98,00 \quad{ }^{\circ} \mathrm{C}$, sedangkan arus yang dihasilkan sebesar 1,46 A. Tegangan ini sudah mampu menyalakan lampu LED namun belum mencukupi tegangan minimum baterai untuk melakukan pengisian daya handphone. Pada menit ke - 60 kompor dinyalakan, besar temperatur sisi panas dari generator termoelectrik yaitu 115,70 ${ }^{\circ} \mathrm{C}$.

Tegangan dan arus yang dihasilkan mampu menyalakan lampu LED lebih terang dari menit ke - 30 dan mampu mengisi daya handphone sebesar 25\% dari semula. Tegangan ini diubah oleh USB buck converter menjadi tegangan output sebesar 3,95V dan arus listrik sebesar 1,52A. Pada menit ke -70 kompor sekam padi dapat menyalakan lampu LED semakin terang dan mampu mengisi daya handphone sebesar 44\% dari semula dengan tegangan $5,29 \mathrm{~V}$ dan arus listrik 2,04A. Tegangan ini diubah oleh USB buck converter menjadi tegangan output sebesar 4,16V dan arus listrik sebesar $1,60 \mathrm{~A}$ dengan temperatur sisi panas $110,90{ }^{\circ} \mathrm{C}$.

Dari tabel 3 dapat dilihat bahwa sistem pembangkit listrik termoelektrik dengan bahan bakar 500 gram sekam padi, pada menit ke - 10 dan menit ke - 20 pembakaran hanya menghasilkan tegangan output sebesar $2,17 \mathrm{~V}$ dan $3,30 \mathrm{~V}$ dengan besar temperatur sisi panas dari generator thermoelectric masing - masing $78,0{ }^{\circ} \mathrm{C}$ dan $96,5^{\circ} \mathrm{C}$. Tegangan yang dihasilkan ini hanya mampu menyalakan lampu LED dengan redup, namun belum mampu mengisi daya baterai handphone sebesar $5 \mathrm{~V}$. Mulai menit ke $-40 \quad$ sistem pembangkit listrik termoelektrik sudah mampu menyalakan lampu LED dan mampu mengisi daya baterai handphone

Tabel 3. Hasil pengujian kompor dengan bahan bakar 500 gram sekam padi

\begin{tabular}{|c|c|c|c|c|c|c|c|c|c|c|}
\hline \multirow{2}{*}{$\begin{array}{l}\text { Waktu } \\
\text { (Menit) }\end{array}$} & \multirow{2}{*}{$\begin{array}{l}\text { Temperatur } \\
\text { Sisi Panas } \\
\left({ }^{\circ} \mathrm{C}\right)\end{array}$} & \multirow{2}{*}{$\begin{array}{c}\text { Temperatur } \\
\text { Sisi Dingin } \\
\left({ }^{\circ} \mathrm{C}\right)\end{array}$} & \multirow{2}{*}{$\begin{array}{c}\begin{array}{c}\text { Selisih } \\
\text { Temperatur }\end{array} \\
\left({ }^{\circ} \mathrm{C}\right)\end{array}$} & \multicolumn{2}{|c|}{$\begin{array}{c}\text { Ouput } \\
\text { Generator } \\
\text { Termoelektrik }\end{array}$} & \multicolumn{2}{|c|}{$\begin{array}{c}\text { Output } \\
\text { USB Back } \\
\text { Converter }\end{array}$} & \multirow[t]{2}{*}{$\begin{array}{l}\text { Indikator } \\
\text { LED }\end{array}$} & \multirow[t]{2}{*}{$\begin{array}{l}\text { Indikator } \\
\text { Charging }\end{array}$} & \multirow{2}{*}{$\begin{array}{c}\begin{array}{c}\text { Pengisiar } \\
\text { Daya }\end{array} \\
(\%)\end{array}$} \\
\hline & & & & $\mathrm{V}(\mathrm{V})$ & $\mathrm{I}(\mathrm{A})$ & $\mathrm{V}(\mathrm{V})$ & $\mathrm{I}(\mathrm{A})$ & & & \\
\hline 10 & 78,00 & 20,00 & 58,00 & 2,17 & 0,84 & 1,38 & 0,53 & Redup & OFF & 0 \\
\hline 20 & 96,50 & 19,50 & 77,00 & 3,30 & 1,27 & 2,43 & 0,94 & Redup & OFF & 0 \\
\hline 30 & 112,20 & 20,00 & 92,20 & 4,00 & 1,54 & 3,04 & 1,17 & Menyala & OFF & 0 \\
\hline 40 & 117,00 & 20,00 & 97,00 & 5,10 & 1,97 & 3,55 & 1,37 & Menyala & $\mathrm{ON}$ & 28 \\
\hline 50 & 123,10 & 19,50 & 103,60 & 5,25 & 2,03 & 4,43 & 1,71 & Menyala & $\mathrm{ON}$ & 35 \\
\hline 60 & 135,00 & 19,00 & 116,00 & 5,47 & 2,11 & 4,90 & 1,89 & Menyala & $\mathrm{ON}$ & 50 \\
\hline 70 & 138,30 & 19,00 & 119,30 & 6,21 & 2,40 & 5,32 & 2,05 & Menyala & $\mathrm{ON}$ & 73 \\
\hline
\end{tabular}


sebesar 5 V. Mulai menit ke - 40 sistem pembangkit listrik termoelektrik sudah mampu menyalakan lampu LED dan mampu mengisi daya baterai handphone sebesar $28 \%$ dari semula dengan tegangan $5,10 \mathrm{~V}$ dan kuat arus listrik 1,97A. Temperatur sisi panas dan dingin dari generator termoelectric masing - masing $117,0^{\circ} \mathrm{C}$ dan $20,0^{\circ} \mathrm{C}$. Tegangan ini diubah oleh USB buck converter menjadi tegangan output sebesar $3,55 \mathrm{~V}$ dan arus listrik sebesar 1,37A. Pada menit ke -70 nyala lampu LED semakin terang dan mampu mengisi daya handphone sebesar $73 \%$ dari semula dengan tegangan $6,21 \mathrm{~V}$ dan arus listrik 2,40A. Tegangan ini diubah oleh USB buck converter menjadi tegangan output sebesar $5,32 \mathrm{~V}$ dan arus sebesar 2,05A dengan temperatur sisi panas $138,30{ }^{\circ} \mathrm{C}$.
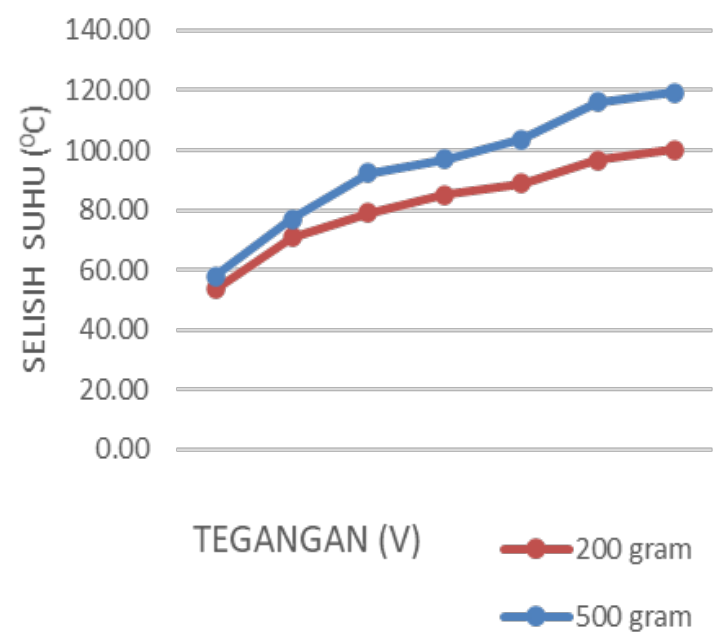

Gambar 4. Grafik karakteristik tegangan output termoelektrik terhadap selisih suhu

Dari grafik diatas dapat dilihat bahwa tegangan output yang dihasilkan generator termoelektrik yang terintegrasi dengan kompor sekam padi dipengaruhi oleh massa sekam padi yang digunakan. Semakin besar massa sekam yang terpakai mengakibatkan peningkatan nilai Fuel Consumption Rate (FCR) [6]. Semakin besar nilai Fuel Consumption Rate (FCR) maka semakin besar pula nilai daya masuk sehingga mengakibatkan turunnya nilai efisiensi kompor sekam mengingat bahwa nilai efisiensi berbanding terbalik dengan nilai daya masukan [5]. Hasil Output sistem pembangkit listrik termoelektrik menggunakan 200 gram sekam padi sistem generator ternyata tidak dapat menjadi tegangan dan arus USB converter berdasarkan arus dan tegangan.

Dari grafik datas, daya output yang dihasilkan thermoelectric generator tersebut sangat kecil sehingga tegangan yang akan digunakan untuk pengisian baterai handphone juga kecil. Arus output dari USB buck converter yang dihasilkan tidak mencukupi untuk pengisian baterai handphone. Tegangan dan arus output generator termoelektrik yang dimasukan kedalam USB buck converter masih belum dapat diubah menjadi tegangan ouput USB buck converter sebesar $5 \mathrm{~V}$. Daya yang masuk kedalam USB buck convert terlalu kecil sehingga alat tersebut mengubah tegangan output menjadi $5 \mathrm{~V}$ dengan besar arus yang sangat kecil, maka dibutuhkan tegangan input yang lebih tinggi supaya daya yang dimasukkan kedalam alat tersebut juga besar. Tegangan input yang lebih dari $5 \mathrm{~V}$ dapat dikonversikan melalui alat tersebut 
menjadi $5 \mathrm{~V}$ dan sisanya diubah untuk menguatkan arus listrik yang dihasilkan untuk pengisian daya baterai.

\section{Simpulan}

Penelitian ini menjelaskan desain kompor sekam padi yang bersih dan hemat energi untuk memasak dan menghasilkan listrik untuk masyarakat di pedesaan yang sederhana dan berbiaya rendah. Generator termoelektrik memanfaatkan prinsip perbedaan temperatur antara sisi dingin dan sisi panas. Sisi panas memanfaatkan panas hasil pembakaran sekam padi dalam kompor dan sisi dingin menggunakan es. Dengan menggunakan 6 modul generator termoelectric yang dirangkai secara seri menghasilkan tegangan $6,21 \mathrm{~V}$ dan arus listrik 2,40 A dengan massa sekam padi 500 gram. Tegangan dihasilkan akan diubah oleh USB buck converter menjadi tegangan $5 \mathrm{~V}$. Arus listrik dan tegangan output yang dihasilkan oleh USB buck converter sebesar 2,05 A dan 5,32V.

\section{Referensi}

1. F. Nawafi, R. D. Puspita, Desna, and Irzaman, "Optimasi Tungku Sekam Skala Industri Kecil Dengan Sistem Boiler," Berk. Fis., vol. 12, no. 3, pp. 77-84, 2010.
2. Handayani, R. T., \& Suryaningsih, S. PENGARUH SUHU KARBONISASI DAN VARIASI KECEPATAN UDARA TERHADAP LAJU PEMBAKARAN BRIKET CAMPURAN SEKAM PADI DAN TONGKOL JAGUNG. Wahana Fisika, 4(2), 98-103

3. C. Lertsatitthanakorn, "Electrical performance analysis and economic evaluation of combined biomass cook stove thermoelectric (BITE) generator," Bioresour. Technol., vol. 98, no. 8, pp. 1670-1674, 2007.

4. R. Y. Nuwayhid, A. Shihadeh, and N. Ghaddar, "Development and testing of a domestic woodstove thermoelectric generator with natural convection cooling," Energy Convers. Manag., vol. 46, no. 910, pp. 1631-1643, 2005.

5. R. Y. Nuwayhid, D. M. Rowe, and G. Min, "Low cost stove-top thermoelectric generator for regions with unreliable electricity supply," Renew. Energy, vol. 28, no. 2, pp. 205-222, 2003.

6. R. Mal, R. Prasad, V. K. Vijay, and A. R. Verma, "The design, development and performance evaluation of thermoelectric generator (TEG) integrated forced draft biomass cookstove," Procedia Comput. Sci., vol. 52, no. 1, pp. 723-729, 2015.

7. C. Favarel, D. Champier, J.-F. Rozis, T. Kousksou, and Jean Pierre Bédécarrats, “Thermoelectricity, a Promising Complementarity with Efficient Stoves in OffGrid-Areas.pdf.” pp. 256-268, 2015 
8. T. Stephen John, "High Efficient Seebeck Thermoelectric Device for Power System Design and Efficiency Calculation: A Review of Potential Household Appliances," Int. J. Comput. Appl., vol. 97, no. 18, pp. 37 $-42,2014$.

9. S. Martino and D. Wulandari, "ANALISIS TRAINER KONVERSI ENERGI PANAS MENJADI ENERGI LISTRIK BERBASIS THERMOELECTRICGENERATOR DENGAN VARIASI PERUBAHAN SUHU," vol. 05, pp. 66-72, 2018.

10. S. Maneewan and S. Chindaruksa, "Thermoelectric power generation system using waste heat from biomass drying," J. Electron. Mater., vol. 38, no. 7, pp. 974-980, 2009. 